\title{
Brand as a cognitive mediator : investigating the effect of media brands as a structural feature of textual news messages
}

\section{Laaksonen, Salla-Maaria}

2019-03-08

Laaksonen , S-M , Falco , A , Salminen, M , Aula , P S \& Ravaja , N 2019 , ' Brand as a cognitive mediator : investigating the effect of media brands as a structural feature of textual news messages ' , Journal of Product and Brand Management, vol. 28 , no. 1, pp. 1-14 . https://doi.org/10.1108/JP

http://hdl.handle.net/10138/300093

https://doi.org/10.1108/JPBM-01-2017-1394

acceptedVersion

Downloaded from Helda, University of Helsinki institutional repository.

This is an electronic reprint of the original article.

This reprint may differ from the original in pagination and typographic detail.

Please cite the original version. 
Running head: BRAND AS A COGNITIVE MEDIATOR

\title{
To cite this document:
}

Salla-Maaria Laaksonen, Alessio Falco, Mikko Salminen, Pekka Aula, Niklas Ravaja, (2019) "Brand as a cognitive mediator: investigating the effect of media brands as a structural feature of textual news messages", Journal of Product \& Brand Management, https://doi.org/10.1108/JPBM-01-2017-1394

\author{
Abstract \\ Purpose \\ This study investigates how media brand knowledge, defined as a structural feature of the \\ message, influences emotional and attentional responses to, and memory of, news messages.
}

Design/methodology/approach

Self-reports, facial electromyography (EMG) and electroencephalography (EEG) were used as indices of emotional valence, arousal and attention in response to 42 news messages, which varied along the valence and involvement dimensions, and were framed with different media brands varying along the familiarity and credibility dimensions.

Findings

Compared to the no-brand condition, news framed with brands elicited more attention. The memory tests indicated that strong media brands override the effect of involvement in information encoding, whereas details of news presented with Facebook were not well encoded. However, the headlines of news framed with Facebook were well retrieved. In addition, negative and high-involvement news elicited higher arousal ratings and corrugator EMG activity. News framed with familiar and high-credibility brands elicited higher arousal ratings. 
Practical implications

Relevant for both brand managers and audiences, the findings show that building credibility and familiarity both work as brand attributes to differentiate media brands and influence information processing.

Originality/value

The results highlight the importance of media brands in news reading: as a structural feature, the brand is used as a proxy to process the message content. The study contributes by investigating how the type of source influences the reception and encoding of the mediated information; by investigating the emotional effects of brands; and by confirming previous findings in media psychology literature.

Keywords: media, brand, LC4MP, emotions, psychophysiology 
Brand as a cognitive mediator: Investigating the effect of media brands as a structural feature of textual news messages

Introduction

The digital era has introduced profound changes in the ways people consume news. First, news is increasingly consumed using electronic devices and thus in a different habitual and technological context than previously. Second, publishing content and establishing media channels has become technically easy, which has led to an increase in the number of media sites or media-like sites. Third, a growing number of people obtain their news through social media platforms, curated by their peers. As a consequence of these developments, the competition among different media has dramatically increased, which has put the media under mounting pressure to find new ways to differentiate. As with other products, one of the main tools for media corporations to differentiate their products is branding (Chan-Olmsted, 2006; Tungate, 2004).

Marketing studies posit that the knowledge consumers possess about a brand is one of the most valuable assets for firms. Brands are signals of quality and credibility: they link to previous experiences with the product and, through them, provide promises of future deliverables (Herbig and Milewicz, 1995; Esch et al., 2006). They are signs designed to communicate attributes and feelings attached to a product beyond its product category and functional value in order to enhance the experienced value (McDowell, 2006). However, media brand management is considered a quite specific area of branding (Krebs and Siegert, 2016), and the understanding of brand effects in media industry is still limited. Following the seminal studies of Hovland et al. (1953, p. 19), who acknowledged that "the impact of a message probably depends also upon the particular publication or channel through which it is 
transmitted", this study investigates how brand knowledge regulates the processing of textual media messages. Hence, we aim to contribute to the growing discussion on media branding and the ways in which media brands can be used as strategic resources in media management (Malmelin and Moisander, 2014; Chan-Olmsted and Shay, 2016). While media branding has several audiences due to the dual market structure of audience and advertising (Sommer, 2015), our main focus is on media consumers and the ways in which elements of the media brand affect the cognitive and emotional processing that takes place when the news is received and processed. Following propositions made in media and advertising research suggesting that the type of channel or source influence the reception and encoding of the information (e.g. Sundar, 2008; Chan-Olmsted and Cha, 2008; Miller and Krosnick, 2000), we expect brands to elicit specific effects in the message processing.

To this end, a psychophysiological methodological approach was selected. Psychophysiology investigates cognitive, emotional and behavioral phenomena related to and revealed through physiological responses (Potter and Bolls, 2012). These responses are measured by using physiological signals such as the activation of facial muscles (facial electromyography EMG) or electrical brain activity (electroencephalography EEG). This methodological approach is expected to reveal brand effects that cannot be investigated by traditional self-reports only (Chartrand, 2005; Schaefer and Rotte, 2007). In particular, psychophysiology allows for the investigation of emotional attachment to brands, which has recently fostered interest among brand researchers (e.g. Wallace et al., 2014; Thomson et al., 2005; Alvarez and Fournier, 2016). Compared to more traditional methods often influenced by socially desirable reporting (Paulhus, 2002), psychophysiology may add to the understanding of the unconscious effects of media brands in particular. In addition, psychophysiological measures have a level of temporal precision over the whole reading situation (Ravaja, 2004). 
Most of the communication studies on textual messages have examined the influence of message content features, such as the emotional valence and relevance of the message to the reader, on emotional and cognitive processes. These studies indicate that negative messages and messages with high perceived relevance to the reader evoke higher attention and cognitive processing, which results in a memory advantage (e.g. Rozin and Royzman, 2001; Schneider and Laurion, 1993). Another line of studies has focused on the structural features of messages, such as content pacing, movements or sudden sounds in videos, and found these aspects to affect cognitive processes (Fox et al., 2004; A. Lang et al., 2002; Sundar and Kalyanaraman, 2004). These studies demonstrate that structural features affect the way the content of the news is processed and encoded. However, the functioning of the brand of a particular media outlet as a structural feature of the news message, and the emotional and attentional psychophysiological responses evoked by it, remain unexplored. In other contexts, however, brands have been shown to elicit bodily responses and emotions during information intake (Esch et al., 2010).

In order to examine the cognitive effects of media brands as message features, this study builds on the limited capacity model of motivated media processing (LC4MP; A. Lang, 2000; 2006), a model that explains cognitive processing during media reception. LC4MP posits that structural features of the media message might influence the activation of the two human motivational systems, and affect how limited resources are allocated to cognitive processing. Following this model, we examined how the media brand, as a structural feature of the message, influences psychophysiological responses to, and memory for, textual news messages. However, as has been shown in relation to other structural features, this effect takes place in connection with the message content features, such as emotional tone and reader involvement. To study these effects in interaction, an experimental setting with selfreported and psychophysiological measurements was used in order to study both the 
conscious and the unconscious emotional and attentional responses elicited by the media brands. Stimulus material consisted of 42 news messages, which varied along the valence and involvement dimensions, and were framed with different media brands that varied along the dimensions of familiarity and credibility. Apart from studying the effects elicited by traditional media brands, messages framed with social media brands were also included to investigate the differences between various media types.

Theoretical background

\section{The limited capacity model of motivated media processing}

The LC4MP, the limited capacity model of motivated media processing (A. Lang, 2000) explains information processing that links media message consumption with motivational tendencies. The main premise of the model is that humans have a limited capacity for information processing, and therefore an automated or controlled allocation of resources must be made. The model posits that during information processing limited resources are allocated across three sub-processes: encoding, storage, and retrieval. Encoding refers to selecting information from the message for further processing, while storage refers to the process of linking new information to old. Retrieval refers to the ability to remember and recall information.

Two motivational systems, the appetitive and the aversive, activate automatically in response to stimuli and influence the sub-processes (Cacioppo and Gardner, 1999; Bradley et al., 2001). In general, positive stimuli activate the appetitive system (approach), while negative stimuli activate the aversive (withdrawal). Although the appetitive system is thought to be slightly more active than the aversive system to support exploration and information intake, at a low level of activation both systems allocate a similar amount of resources to the sub-processes (A. Lang, 2000; Bradley et al., 2001). However, the aversive system tends to activate more quickly and generate stronger responses, which in turn increases the allocation 
of resources to encoding, storage and retrieval. This refers to the phenomenon known as negativity bias, which indicates that, when compared to positive news, negative and especially extremely negative news prompts more attention and cognitive processing than positive news (Baumeister et al., 2001; Grabe et al., 2003). Following Rozin and Royzman (2001), the term negativity informational effect is used here to refer to the generic phenomenon, which encompasses various affective and informational effects.

In addition, A. Lang (2000) posits that other structural features might influence the activation of the two motivational systems. For example, studies have shown that the complexity of the message structure (A. Lang et al., 2013a), camera angle changes (A. Lang et al., 2000), or pitch variations (Rodero et al., 2017) affect the allocation of cognitive resources. Studies have also investigated the structural features present in online environments, such as different page styles or surfing patterns (e.g. Wise et al., 2013). However, structural features are always linked to the message content, and are also affected by motivational factors related to the message consumption, such as the relevance of the message topic to the reader.

\section{Emotions and involvement in media consumption}

Several studies have examined and highlighted emotion-related responses during textual news message reading. Emotions are biologically-based action dispositions consisting of three components: subjective feeling, physiological responses, and expressive behavior. Some scholars have added cognitive appraisal and motivational state to these three components (P. Lang, 1995). The components of the emotional space have been mapped with two orthogonal dimensions by the circumplex model proposed by Russel (1980): emotional valence ranges on a continuum between pleasantness and unpleasantness, whereas the arousal dimension ranges from calm to excited. This model is the basis of facial electromyography 
EMG, which is used to study the hedonic valence of affective processes (Tassinary and Cacioppo, 2000).

Further, research suggests that specific facial muscle groups are responsible for the expression of positive and negative emotions, and supports the view that the emotional tone of the message is an important factor that affects the reader's psychophysiological responses (Ravaja, 2004). During textual news reading, increased activity in the orbicularis oculi and zygomaticus major, and decreased activity in the corrugator supercilii muscle regions have been associated with positive emotions (Ravaja, 2004; Tassinary and Cacioppo, 2000).

Based on these studies, we propose the following hypothesis:

H1a. Compared to extremely negative news and negative news, positive news will elicit higher zygomaticus major and orbicularis oculi, and lower corrugator supercilii facial EMG activation.

In addition to facial EMG, the electroencephalography EEG alpha power $(8-13 \mathrm{~Hz})$ correlates inversely with attention, emotional arousal, interest and recall (Klimesch, 1999; Simons et al., 2003). Further, the approach-withdrawal motivation model of emotion posits that the left and right brain regions are parts of two separate systems underlying approach and withdrawal motivation, respectively (e.g. Davidson, 2003). Relatively greater left frontal alpha activity indicates a propensity to approach or engage with the stimulus, whereas relatively greater right frontal alpha activity indicates a propensity to withdraw/disengage from the stimulus (Coan and Allen, 2004; Harmon-Jones, 2003).

The LC4MP model as well as other research on information processing acknowledge the greater influence of negative and arousing stimuli over positive ones (A. Lang, 2000; Newhagen and Reeves, 1992; Schneider and Laurion, 1993). This refers to the informational negativity effect: negative and arousing events prompt more cognitive processing and attention. Consistently, deeper cognitive processing and attention to negative stimuli, such as 
announcements, advertisements, and images, is often associated with better memory ( $\mathrm{P}$. Lang, et al., 1993; Newhagen and Reeves, 1992; Bolls et al., 2001; Grabe et al., 2003). Therefore, we propose the following hypotheses:

H1b. Compared to positive news, extremely negative and negative news will evoke relatively greater right frontal EEG alpha activation and decreased EEG alpha power.

H1c: Compared to positive news, extremely negative and negative news will be better encoded and retrieved from memory.

Apart from emotions, the involvement of the reader has been considered a relevant content-related factor influencing information encoding. This study conceptualizes involvement as the relevance of the message to the reader. The LC4MP model posits that news involvement regulates the activation of the two motivational systems and resource allocation, which in turn influence memory (A. Lang, 2000). Schneider and Laurion (1993) found that high-involvement news messages have an attentional and memory advantage over low-involvement messages. In line with this finding, also Kätsyri and others (2012) that when compared to low-involvement news, high-involvement news evokes higher arousal ratings and attention, which lead to greater information intake. Therefore, we expect highinvolvement news to be differentiated by the self-reports and by the psychophysiological measurements:

H2a. When compared to low-involvement news, high-involvement news will elicit increased self-reported arousal.

H2b. When compared to low-involvement news, high-involvement news will elicit decreased whole-head EEG alpha power and greater relative left frontal EEG activation.

H2c. When compared to low-involvement news, high-involvement news will be better encoded and retrieved from memory. 
Another substantial focus within LC4MP research has been to examine which structural features of the message, such as screen size or graphical elements, influence the activation of the motivational systems and the allocation of resources to the memory subprocesses (A. Lang et al., 2002; A. Lang et al., 2013a). Advertising studies have also demonstrated that the features of the message source, such as credibility or familiarity, influence the perception and processing of news content (Schumann and Thorson, 1990), a notion particularly used to evaluate the effects of the media context and effectiveness of sponsorship in consumer psychology studies (Moorman et al., 2002).

We suggest that the message source is most commonly present in media consumption as the brand of that particular media. Brand is a symbol intended to identify and differentiate products and services from those of competitors (Fournier, 1998; Keller, 2003). According to Keller (2003), brand knowledge exerts its influence through two components, brand awareness and brand image. Brand awareness indicates how strongly consumers identify and recognize the brand. Brand image relates to the perceptions of the brand as reflected by brand associations in consumers' minds. These associations are brand-related attributes, benefits and attitudes, such as favorability, strength, and uniqueness.

For media brands, good quality, in particular, is a desired attribute of the identity of a strong brand (Siegert et al., 2011; Krebs, 2017). Further, in the context of media consumption, a significant brand-related overall attitude is media credibility, as emphasized by studies explaining readers' relationships to the media (Flanagin and Metzger, 2007; Kohring and Matthes, 2007). Credibility defines the degree to which consumers believe in the media brand's trustworthiness and expertise (Goldsmith et al., 2000). This makes media credibility a construct based on accumulated knowledge of the actions of the media, namely a construct based on the quality of previous news-reading experiences of that particular media. Hence, the relationship between media brand and customers is mediated by somewhat 
different factors than those explaining customer relationships with regular brands (cf. Krebs, 2017). In the current study, media brand knowledge is operationalized using two dimensions of brand knowledge applied to the context of the media industry: familiarity with the brand, measuring brand awareness, and the credibility of the brand, measuring brand image.

Brand image is not only identified using cognitive appraisals and attributes. Credibility, for instance, is affected by both cognitive and affective evaluations (Johnson and Grayson, 2005). Furthermore, emotional responses to brands are used as cues for inferring quality and affect consumer choices (Soscia, 2007; Loewenstein and Lerner, 2003; Thomson et al., 2015). Positive brands have been associated with higher degrees of pleasantness, positive emotions and approach tendencies (Walla et al., 2011), which are positively related to positive outcomes such as word-of-mouth intentions, and which foster long-term relationships with the brand (Alvarez and Fournier, 2016; Carroll and Ahuvia, 2006; Veloutsou and Moutinho, 2009). Further, strong brands display higher unaided recall and stronger positive association (Hoeffler and Keller, 2003). It appears that customer satisfaction or delight is characterized by the experience of positive and arousing emotions (Brakus et al., 2009).

Building on the LC4MP model, and the studies highlighting the emotional dimensions of the brand relationship, we expect brand familiarity and credibility to influence the individual emotion-related physiological responses:

H3a. Compared to unfamiliar and low-credibility brands, news framed with familiar and high-credibility brands will elicit higher degrees of self-reported pleasantness and arousal.

H3b. Compared to unfamiliar and low-credibility brands, news framed with familiar and high-credibility brands will elicit higher zygomaticus major and orbicularis oculi, and lower corrugator supercilii EMG activity. 
Following the ideas present in LC4MP in relation to the structural features of the message and in line with Esch et al. (2012), who showed that activations in brain areas associated with information retrieval were higher for strong brands, we argue that the visual cues that represent the media brand, and link to the reader's previous experiences with the brand, also act as a structural feature of the message. We suggest that, like other media structural features, familiarity and credibility elicit different degrees of resource allocation to the encoding and retrieval processes (A. Lang, 2000; A. Lang et al., 2002), namely that highcredibility familiar brands will increase the attention given to the message:

H3c. Compared to unfamiliar and low-credibility brands, news framed with familiar and high-credibility brands will elicit decreased whole-head EEG alpha power and relatively greater left frontal EEG activation.

H3d. Compared to unfamiliar and low-credibility media brands, news framed with familiar and high-credibility brands will be better encoded and retrieved from memory.

The hypotheses above suggest that there will be significant main effects in terms of media brands, news valence, and comment valence in predicting self-report responses. However, it is also possible that there will be interactions between media brand dimensions and news-message valence and involvement in predicting these variables. Thus, we formulate the first research question as follows:

RQ1: Is there an interaction between media-brand and news-message valence and involvement in predicting self-reported and physiological responses or memory?

\section{Traditional media and social media}

The current media landscape is profoundly marked by the role of social media, which are increasingly used as platforms for information and news dissemination (Villi et al., 2016; Chan-Olmsted, 2011). Studies have shown that sources other than traditional media are interfering with the ways in which readers evaluate representativeness and the quality of online 
news messages (Kang and Sundar, 2016). It can be assumed that certain differences arise when news information is acquired through a platform characterized by peer production. While studies investigating the psychophysiological responses elicited by social media messages are emerging (e.g. Alhabash et al., 2018; Ravaja et al., 2015; Mauri et al., 2011), the responses to news posted as or within social media messages have not been widely studied. The present study addresses this gap by examining how social media brands, in comparison with traditional media brands, affect the reader's responses when they are presented as the message source. Hence, we pose the second research question as follows:

RQ2. Does news framed with traditional media brands and news framed with social media brands evoke different degrees of self-reported pleasantness and arousal, psychophysiological responses, and memory?

\section{Methodology}

The current study used psychophysiology, a novel method used to study the effects of media brand knowledge — a structural feature of the message — on the emotional and cognitive processes activated during news reading. Self-reports, facial electromyography (EMG), and electroencephalography (EEG) were utilized in order to assess emotional valence, emotional arousal, and attention. Stimulus material consisted of 42 news messages, which varied along the valence (i.e. pleasantness) and involvement (i.e. relevance to the reader) dimensions, and were framed with different media brands that varied along the dimensions of familiarity and credibility. The following sections explain the variables and manipulations as well as the experimental procedure.

\section{Participants}

Participants were recruited who identified themselves as persons who mainly read news online. Participation was compensated with two movie tickets. The participants comprised 74 Finnish students $(M=24, S D=2.74$, 52 female, 22 male, aged 19-30), a 
number typical of similar studies (e.g. Ravaja, 2004; Kätsyri et al., 2012). Given that the EEG data were partly unusable for some participants, the number of participants totaled 68 in the final EEG analyses.

\section{Design}

A 3 (news valence: positive, negative, extremely negative) $\times 2$ (news involvement: low, high $) \times 7$ (media brand: six brands, a control condition) within-subject design was used. To counterbalance the assignment of news to the 7 brand conditions, a $7 \times 7$ Latin square was used. The same Latin square was replicated for the 6 news conditions ( 3 news valence $\times 2$ news involvement).

\section{Materials}

News messages. The stimuli consisted of 42 fictional Finnish language news messages, the content of which varied along two dimensions: emotional valence and involvement. Each news message consisted of a short headline and a message body. An effort was made to use messages that would elicit a wide range of ratings along the valence and involvement dimensions. Twenty-eight news messages were selected from an existing stimulus set prepared and tested in two previous studies (Ravaja et al., 2006; Kätsyri et al., 2012). These included seven positive and seven negative high-involvement messages, as well as seven positive and seven negative low-involvement messages. High-involvement news messages dealt with issues relevant to young students (e.g. Student grants will finally be increased); low-involvement messages dealt with issues relevant to the elderly (e.g. New services for elderly in Kamppi service center). In addition, fourteen extremely negative news stories (i.e. violent crime news) were selected from real newspapers. To generate a similar variation of involvement, the message content was edited to represent either the high-involvement category (e.g. Young woman beaten to death in suburban flat), or the low-involvement category (e.g. Elderly man assaulted at taxi rank), with seven messages each. Despite the fact 
that online news increasingly contains visual material, the news was only presented textually since the majority of news is still presented and read in a textual format. Furthermore, the study aimed to contribute to and compare with the existing stream of studies investigating responses to textual messages.

Media brands. The media brands were selected on the basis of a nationwide survey reporting the reputation and credibility of Finnish media brands (Aula et al., 2014), using the scores along the familiarity and credibility dimensions. A brand was selected for each of the four categories defined by familiarity-credibility combinations: high-familiarity and highcredibility national media (Helsingin Sanomat, a well-known national newspaper), lowfamiliarity and low-credibility political media (Tiedonantaja, a less-known political newspaper), high-familiarity and low-credibility tabloid media (Iltalehti, a well-known tabloid) and low-familiarity high-credibility local media (Savon Sanomat, a local daily newspaper). In addition, we selected Facebook to represent a familiar social media brand, whereas a random blog (Uutisvirta, "News feed") was created to represent an unfamiliar social media brand. The credibility dimension was excluded because for social media brands no corresponding credibility indices exist. Further, in order to support the ecological validity of the experimental setting, we limited our selection to those social media brands where a message the length of a news story could plausibly be published, namely Facebook or blogs. For all media, brand frames were assembled to resemble mobile news sites (Figure 1). Twenty-four pre-test participants rated the brands along emotional valence, arousal, familiarity and credibility dimensions using 9-point scales. The media brands were significantly differentiated by the dimensions, $F(5,2462.97)=671.94, p=<.001$.

FIGURE 1 HERE 
After reading a description of the experiment, each participant filled out an informed consent form together with a demographic questionnaire, followed by a three-minute rest period during which baseline psychophysiological measurements were taken. Each participant was presented with 42 trials, in random order, each of which consisted of the following phases: (a) a news message framed with a media brand, (b) valence, arousal and involvement self-reports, and (c) an inter-stimulus interval varying randomly from two to six seconds, during which the screen was blank. Each news message remained on the screen until the participant pressed enter. At the end of the reading session, memory was tested. In addition, the participant evaluated each media brand's familiarity and credibility. In total, the experiment lasted for 1.5-2 hours.

\section{Self-report measures}

A set of six self-report measures was chosen to reflect the variables hypothesized to have significant effects based on existing studies (referenced for H1-H3) on motivated mediated message processing.

Emotional valence and arousal. Participants rated their emotional reactions to the news messages in terms of valence and arousal using 9-point pictorial scales (SAM, see P. Lang, 1980). Both scales consisted of human figures expressing different states of emotional arousal.

Involvement. Involvement with the news message was assessed using the sum of two items: How interesting was the news message? and How relevant was the news message for you?. Participants rated their reactions using 7-point scales, ranging from 1 (not interesting/relevant at all) to 7 (very interesting/relevant).

Media familiarity and credibility. As the final part of the experiment, after the memory tests, participants rated the media frames along the familiarity and credibility 
dimensions using 9-point scales ranging from not at all familiar/credible to highly familiar/credible.

\section{Memory tests}

Two memory tests were conducted to measure the retrieval and encoding of the message content. A free recall memory test assessed retrieval. The participants were asked to write down all the headlines they could remember. The messages noted by the participants were checked for correctness and given a score of one when the main point was recalled and a score of zero otherwise. After the free recall memory test, we conducted a multiple-choice memory test, a previously identified valid measure of encoding effectiveness (e.g. Zechmeister and Nyberg, 1982). The test consisted of 42 message headlines presented in random order, followed by a set of four statements, only one of which was correct. The answers were checked and given a score of one when the answer was correct. The memory tests were always conducted in this order to correctly measure recall without priming the participants with the multiple-choice options.

\section{Physiological data collection}

Physiological signals were recorded with a 40-channel Brain Vision QuickAmp amplifier. EEG activity was recorded on left and right frontal (F3, F4), central (C3, C4), temporal (T7, T8), parietal (P3, P4), and occipital (O1, O2) scalp sites (10-20 International System; Jasper, 1958). A common reference montage was used during the recordings and the ground electrode was placed at FCz. Electrode impedances were reduced to less than $5 \mathrm{k} \Omega$. During the data collection, 1-Hz high-pass and 200-Hz low-pass filters were used; a $50-\mathrm{Hz}$ notch filter was also employed.

Facial EMG activity was recorded in the left corrugator supercilii, orbicularis oculi and zygomaticus major muscle regions as recommended by Fridlund and Cacioppo (1986). The raw EMG signal was amplified, and frequencies below $30 \mathrm{~Hz}$ and above $400 \mathrm{~Hz}$ were 
filtered out. The raw signal was digitally rectified and integrated over $1000 \mathrm{~ms}$. The data collection was controlled by Brain Vision Recorder software and the sampling rate was 2,000 Hz.

\section{Data reduction and statistical analyses}

After the recordings, the EEG data were filtered with $0.5-\mathrm{Hz}$ high-pass and $70-\mathrm{Hz}$ low-pass filters. The EMG raw signal was digitally rectified and integrated over 1000 ms. For each trial, the EEG and facial EMG data were segmented into sixteen 1-s epochs, including one second preceding the onset of the news message (baseline) and fifteen seconds after news message onset. For artifact removal in the EEG data, all epochs containing activity outside the range of $-85 \mu \mathrm{V}$ to $+85 \mu \mathrm{V}$, on any of the EEG or EOG channels, were detected and removed from further analyses. The power spectra were derived by the fast Fourier transform (FFT) method with a Hanning window (applied to the distal 10\% at each end of the epoch). Power values (in $\left.\mu \mathrm{V}^{2}\right)$ within the alpha $(8-13 \mathrm{~Hz})$ frequency range were extracted for each epoch. Mean values were calculated for each 1-s epoch and they were then aggregated into four single epochs: baseline (second preceding the onset of the news message) and three 5-s epochs during the presentation of the news messages. As in previous research (Allen et al., 2004), a frontal asymmetry index $(\ln (\mathrm{F} 4)-\ln (\mathrm{F} 3))$ was computed for each period. As alpha power is inversely related to cortical activity (Lindsley and Wicke, 1974), higher scores on the index indicate greater relative left hemisphere activity. Further, mean values were calculated for the central $(\mathrm{C} 3, \mathrm{C} 4)$, parietal $(\mathrm{P} 3, \mathrm{P} 4)$, and occipital $(\mathrm{O} 1, \mathrm{O} 2)$ sites for the alpha frequency band $(8-13 \mathrm{~Hz})$. Whole-head alpha activity was calculated as a mean alpha activity of all recording sites. Logarithmic transformations were conducted for facial EMG data to normalize the distributions.

All data with the exception of the free recall memory test were analyzed with the Linear Mixed Models procedure with restricted maximum likelihood estimation. The data 
from the free recall memory test were analyzed with the General Linear Model procedure with repeated measures using Bonferroni corrections. When analyzing physiological data, participant ID was specified as the subject variable, the sequence number of a news message (1 to 42 ) and epoch (1 to 3 ) were specified as the repeated variables, and AR(1) was specified as the covariance structure for the residuals. A fixed-effects model that included the baseline (Second 1) physiological value, epoch, news message valence, involvement, and media frame, and all two-way interactions among the latter three variables were specified. The effects of age and gender were tested in the analysis, but as no significant main effects were found, they were dropped from the model. When analyzing self-report data, heterogeneous compound symmetry was specified as the covariance structure for the residuals (there were no epochs, baseline). The hypotheses and research questions regarding the influence of the media brands on the individual emotional and cognitive responses were tested using five planned contrasts (see Table 1).

TABLE 1 HERE

Results

\section{Manipulation check}

Tables 2 and 3 show the means for the study variables by a priori news valence and involvement. The main effect of a priori news valence had a significant effect in predicting valence and arousal ratings, $F(2,2969.46)=2346.59, p<.001$, and $F(2,2934.09)=10.70, p<$ .001 , respectively. Valence ratings were higher for positive news compared to negative and extremely negative news, all $p s<.001$. The interaction between $a$ priori news valence and news involvement had a significant effect in predicting valence ratings, $F(2,2967.82)=$ $53.00, p<.001$. That is to say that high-involvement positive news elicited higher valence ratings compared to low-involvement positive news, whereas high-involvement negative news elicited lower valence ratings compared to low-involvement negative news. 
Involvement ratings were significantly higher for high-involvement compared to lowinvolvement news, $F(1,2967.71)=857.84, p<.001$. The interaction between news valence and involvement was significant for involvement ratings, $F(2,2958.13)=68.20, p<.001$, in that the difference between high-involvement and low-involvement news in self-reported involvement was more pronounced for positive and negative news compared to extremely negative news.

The main effect for media brand was significant in predicting self-reported media credibility, $F(5,349.247)=94.43, p<.001$. Media brand credibility ratings were higher for high-credibility (traditional) media brands compared to low-credibility (traditional) brands. The main effect for media brand was also significant in predicting self-reported media familiarity, $F(5,338.38)=187.27, p<.001$. Familiarity ratings were higher for familiar (traditional) media brands compared to unfamiliar (traditional) media brands, $p<.001$, as well as for a familiar social media brand (Facebook) compared to the unknown blog, $p<.001$. Further, credibility ratings were lower for Facebook compared to all traditional media brands $\mathrm{F}(5,2466.05)=672,75, p<.001$.

\section{TABLE 2 HERE}

\section{Effects of news content characteristics}

The main effect of the emotional valence of news messages was significant in predicting orbicularis oculi EMG activity, $F(2,2974.30)=3.93, p=.020($ H1a). Pairwise comparisons indicated that, when compared to extremely negative news, positive news evoked greater orbicularis oculi activity, $p=.017$. Furthermore, there was a significant main effect of news message emotional valence in predicting corrugator EMG activity, $F(2$, $2971.40)=63.01, p<.001$. Pairwise comparisons indicated that, when compared to positive news, extremely negative and negative news messages evoked increased corrugator supercilii responses, $p<.001$ and $p=.002$, respectively. In addition, when compared to negative news, 
extremely negative news evoked higher corrugator EMG activity, $p<.001$. There was also a significant main effect of emotional valence for zygomaticus major EMG activity, $F(2$, 2973.83) $=3.01, p=.049$, but pairwise comparisons were non-significant.

H1b predicted that, compared to positive news, extremely negative and negative news would evoke greater relative right frontal EEG activation and decreased whole-head EEG alpha. The main effect of news message emotional valence was significant in predicting frontal alpha asymmetry, $F(2,1360.09)=4.52, p=.011$. Pairwise comparisons indicated that, compared to negative news, extremely negative news evoked relatively greater right frontal activation, $p=.012$. However, there was no significant difference between positive news and negative news, or between positive news and extremely negative news. The emotional valence of messages had no influence on EEG alpha activity, $F(2,1402.32)=.09, p=.910$.

The main effect of news message emotional valence was significant in predicting recognition memory, $F(2,2676.30)=9.32, p<.001(\mathrm{H} 1 \mathrm{c})$. Pairwise comparisons indicated that recognition memory was better for negative news compared to positive and extremely negative news, $p<.001$ and $p=.010$, respectively. However, there was no significant difference between positive and extremely negative news. The emotional valence of news messages was not associated with free recall, $p=.218$.

H2a predicted that, compared to low-involvement news messages, high-involvement messages would evoke higher self-reported arousal. The hypothesis was confirmed, $F(1$, $2946.03)=245.04, p<.001$.

$\mathrm{H} 2 \mathrm{~b}$ predicted that, compared to low-involvement news, reading high-involvement news would elicit decreased whole-head EEG alpha power and greater relative left frontal EEG activation. The hypothesis was not supported, $F(1,1398.36)=2.40, p=.121$, and $F(1,1354.78)=.57, p=.449$, respectively. However, although not hypothesized, high- 
involvement news elicited higher corrugator supercilii facial EMG activity compared to lowinvolvement news, $F(1,2971.43)=4.07, p=.044$.

$\mathrm{H} 2 \mathrm{c}$ predicted that recognition memory and free recall would be better for highinvolvement messages compared to low-involvement messages. The hypothesis was not supported: the main effect for high-involvement news messages was significant for the multiple-choice memory test, $F(2678.46)=11.69, p=.001$, but with an interaction with the media brand (see H3d). Further, the free recall memory test indicated that when compared to high-involvement news, low-involvement news was retrieved better, $\mathrm{p}<.001$.

\section{Effects of media brands}

H3a predicted that, compared to unfamiliar and low-credibility media brands, familiar and high-credibility media brands would elicit higher self-reported valence and arousal. Contrary to our expectations, the media brands were not differentiated by emotional valence ratings, $F(6,2993.91)=0.89, p=.499$ (Table 3). However, the media brands were differentiated by self-reported arousal, $F(6,2958.68)=2.32, p=.031$. Contrast 3 indicated that familiar traditional brands elicited higher arousal ratings compared to unfamiliar traditional brands, $F(1,6)=2.32, p=.006$. High-credibility traditional media brands elicited higher arousal ratings compared to low-credibility traditional brands, although the difference failed to reach statistical significance, Contrast $4 F(1,6)=2.32, p=.082$.

$\mathrm{H} 3 \mathrm{~b}$ predicted that, compared to unfamiliar and low-credibility brands, news framed with familiar and high-credibility brands will elicit higher zygomatic major and orbicularis oculi, and lower corrugator supercilii EMG activity. The media brands were not significant in predicting the zygomatic $F(6,3005.60)=0.26, p=.953$, corrugator $F(6,3002.74)=0.92, p=$ .479 , or orbicularis $\mathrm{F}(6,3006.13)=.35, p=.905 \mathrm{EMG}$ muscles.

$\mathrm{H} 3 \mathrm{c}$ predicted that, compared to unfamiliar and low-credibility media brands, familiar and high-credibility media brands would elicit decreased whole-head EEG alpha and greater 
relative left frontal alpha activity. The hypothesis was not supported, $F(6,1430.27)=1.19, p$ $=.311$, and $F(6,1390.77)=1.62, p=.139$, for whole-head EEG alpha power and frontal EEG asymmetry, respectively. It is of note that, although the main effect of media brands was non-significant, news framed with media brands elicited decreased frontal EEG alpha power compared to news with the control condition, for Contrast $1, F(1,6)=1.56, p=.050$.

H3d predicted that recognition memory and free recall would be better for familiar and high-credibility traditional media brands compared to unfamiliar low-credibility traditional media brands. The main effect of brand was significant in predicting recognition memory, $F(6,2706.28)=2.40, p=.025$. However, this result is disqualified by the significant interaction between media brand and news involvement for the multiple-choice memory test $(F(6,2588.06)=2.37, p=.027$, see Figure 2$)$. The result indicates that highfamiliarity national media and the tabloid brand prompted better encoding memory for lowinvolvement news, while for all other brands memory was better for high-involvement news. Recognition memory was better for news framed with high-credibility media brands compared to news framed with low-credibility brands, although Contrast 4 narrowly failed to reach statistical significance, $F(1,6)=2.40, p=.059$. Contrast 5 indicated that, compared to the familiar social media brand, traditional media brands elicited better recognition memory, $F(1,6)=2.40, p=.017$. However, the results from the free recall memory test indicate a significant main effect of the media brand in predicting retrieval memory $\mathrm{F}(6)=24.77, p<$ .001 . News framed with Facebook was recalled significantly better when compared to news framed with the unfamiliar social media and low-credibility traditional media, and almost significantly compared to low-credibility unknown traditional media, $p<.005, p<.005$ and $p$ $<.069$, respectively (Table 3 ).

\section{TABLE 3 HERE}

FIGURE 2 HERE 
Discussion

This study investigated the moderating effect of media brand knowledge in the processing of textual news messages. The findings suggest that the media brand acts as a structural feature of the media message and influences the processing of the news. This effect, however, is shown in the memory tests and self-reported arousal ratings, but only marginally in the physiological data. Hence, it seems the influence of the brand is less physiological, and more related to cognitive considerations than unconscious emotional responses. However, several other findings emerged in the psychophysiology: we confirmed the notion of negativity bias in relation to news message valence, and highlight the importance of the content relevance to the reader's attention, self-reported arousal, and memory.

News message, emotion and motivation

When it comes to responses to the news content features of the news messages, the study confirmed the results from previous investigations examining self-reported and physiological responses, and memory for news messages. We found higher self-reported pleasantness and increased zygomatic and orbicularis EMG activity in response to positive news messages, and higher arousal ratings and increased corrugator EMG activity in response to negative and extremely negative news. Although corrugator EMG activity is often associated with negative emotions, it has also been shown to increase during attentional engagement (Cohen et al., 1992). Furthermore, when compared to negative news, extremely negative news evoked relatively greater right frontal activation, which implies the activation of the aversive system. Consistently, negative news was encoded better. This is in line with the LC4MP model, which suggests that low levels of negative-arousing content increase resources allocated to storage (A. Lang, 2000).

As expected, motivationally relevant news elicited higher arousal ratings and increased corrugator EMG activity, which was partly supported by the multiple-choice 
memory test results. However, the free recall memory test indicates that low-involvement news messages were retrieved better. It is possible that while high-involvement news messages lead to encoding and storing details, low-involvement messages facilitate encoding and storing the content at a more general level. All in all, the findings confirm that contentrelated features influence the processing of and memory for news messages.

\section{Media brands}

Media brands had an influence on the self-reported arousal and frontal EEG alpha activity, which consistently influenced the three memory sub-processes. The familiarity and credibility dimensions of the brand were not significant in predicting self-reported valence and facial EMG activity. Nevertheless, news framed with familiar and credible media brands prompted higher arousal ratings, although the difference between high- and low-credibility brands failed to reach statistical significance. This finding is in line with previous studies showing that in addition to positive emotional responses, familiar strong brands include an arousal component (Carroll and Ahuvia, 2006; Thomson et al., 2005).

When compared to the no-brand condition, reading news framed with media brands prompted lower frontal EEG activity, and therefore more attention. In line with this finding, the main effect from the recognition memory test suggests that participants better encoded, stored and retrieved the content and details of news framed with traditional media brands, especially high-credibility brands. One explanation for this finding is that participants regarded the popular social media as an untrustworthy source - a notion also confirmed by the manipulation check. However, the free recall memory test indicated that the content of news framed with Facebook was retrieved better than the content of news framed with the blog, or with the low-credibility unknown traditional media brand. In this sense, strong media brands work psychologically as differentiating agents to promote particular brand identities 
(cf. Siegert et al. 2011; Malmelin and Moisander, 2014), and the differentiation functions between traditional but also between social media brands.

What adds to the complexity of the relationship between media brands and involvement is that brands work in interaction with news involvement. While in general news with high-involvement content was encoded better, as indexed by the multiple-choice memory test, the interaction analysis revealed that when presented with familiar media brands, details of low-involvement news were better memorized. It seems that strong, familiar and credible media brands, particularly the strong national media brand, elicit a mode of news reading where cognitive resources are allocated to encode information independent of the relevance of the news content to the reader. This effect overrides the otherwise significant effect of news involvement, and hence presents a contradictory result compared to previous studies, which highlight the importance of content relevance for information processing.

Facebook was not differentiated from other media brands in any other regard except in the memory tests, where, to our surprise, the results were contradictory. Although the effect was not evident in the physiological data, the results suggest that when it comes to memory, traditional and especially credible media brands led to a deeper acquisition of the news details, but Facebook prompted a more superficial processing of the whole news - or the news headline. Hence, while the Facebook brand draws the attention of readers, it does not invite attention to the news details. This is particularly evident when investigating the interaction between brands and involvement; details of low-involvement news presented via Facebook were the least retrieved (Figure 2). Thus, the present finding is in line with what we assumed in RQ2; traditional and social media brands evoke different processing in regard to news messages. Further research is needed to examine the influence of social media brands as media brands in news consumption. In reality, such a news consumption situation often 
includes multiple media brands present at the same time, for example when news is shared in social media, which makes the situation more complex.

Overall, the results highlight the assumed importance of media brands in digital environments; as a structural feature, the media brand is used as a proxy to process the content of the message. First, any media brand accompanying a news message increased attention, and familiar brands also fostered information encoding. Second, traditional credible media brands elicited stronger arousal responses, which in turn increased the resources allocated to information storage and retrieval as indexed by the free recall test. However, when compared to the influence exerted by the news message valence and involvement, the media brand influence was considerably more subtle.

\section{Limitations}

Certain limitations existed in the research setting. First, an experimental setting sets limits on the ecological validity of the study. A laboratory setting cannot fully imitate rich online media; for example, in order to ensure the validity of the measurements, simplistic versions of the stimuli are needed. Further, as the experiment lasts for some time, participants may have felt tired towards the end of the experiment. The presentation order of the stimulus material was randomized for each participant to ensure that there would be no systematic fatigue or habituation effects.

Second, the findings are limited to an experimental within-subject setting with a rather small number of participants, who are young digital natives. We aimed to counterbalance learning effects common to within-subject studies by using a double Latin square rotation in the stimulus presentation. As the participants represent a similar population, it can be expected that they share somewhat similar news reading habits and technical skills. Nevertheless, similar studies with larger samples and different demographics would shed more light on the moderating effect of media brands. 
Third, our conceptualization of reader involvement was operationalized as social group-related topical relevance. Including considerations such as the reader's interest in environmental issues or employment policies would add more detailed knowledge regarding the complexity of involvement. Further, regarding the premises of LC4MP, the study did not take into consideration the reader's goal as a factor affecting cognitive processes (cf. A. Lang et al., 2013b), as the participants had no control over what to read. Other methods, such as qualitative observation approaches could be used to examine how users navigate their news in the presence of various media brands.

Finally, it is likely that the influence of the media brands was to some extent disguised by the message content effects, which would correspond to the findings of Krebs (2017). We cannot exclude the possibility that more emotionally relevant or provocative media brands would have had a stronger impact on the reader. The brand selection was restricted to media brands that were reconcilable with the news content in an ecologically valid way.

\section{Social and practical implications}

Despite the limitations, the study demonstrated that reading experience and perception of the news depend not only upon news content features, but also on brand knowledge and the psychophysiological responses elicited by them. This is a finding with relevance both for media companies considering their brand-building strategies as well as for news readers. Strategic approaches to branding in the media industry have been rather narrow and limited (Malmelin and Moisander, 2014). For brand managers, the most important takeaway from this study is that credibility and familiarity both function as brand attributes to differentiate media brands. More studies are needed to investigate how media brand credibility is formed as a psychological element, and how it can be built and managed. Nonetheless, we suggest 
that media companies should pay attention to branding and long-term reputation-building in their strategies for fostering reader relationships.

The most important implications of this study, however, concern the news consumers; the cognitive and emotional processes that occur while they are reading the news are affected not only by the message characteristics, but also by the media brand. Awareness of the cognitive influence of media brands is relevant for readers to develop cognitive skills to control their own information acquisition. For instance, our findings indicate that any information that is presented framed with a strong media brand is more thoroughly processed, which might be problematic, for example, if a quality-media brand is used in a false context. This has profound consequences for how information is accumulated at an individual and at a social level, and calls for media education interventions.

\section{References}

Alhabash, S., Almutairi, N., Lou, C. and Kim, W. (2018), "Pathways to Virality: Psychophysiological Responses Preceding Likes, Shares, Comments, and Status Updates on Facebook", Media Psychology, doi:10.1080/15213269.2017.1416296.

Allen, J., Coan, J. and Nazarian, M. (2004), "Issues and assumptions on the road from raw signals to metrics of frontal EEG asymmetry in emotion”, Biological Psychology, Vol. 67 No. $1-2$, pp. $183-218$.

Alvarez, C. and Fournier, S. (2016), “Consumers' relationships with brands", Current Opinion in Psychology, Vol. 10, pp. 129-135.

Aula, P., Laaksonen, S-M., Ravaja, N., Salminen, M. and Falco, A. (2014), Mediamaine. Communication Research Centre Research report 2/2014, University of Helsinki, Helsinki. 
Baumeister, R., Bratslavsky, E., Finkenauer, C. and Vohs, K. (2001), "Bad is stronger than good", Review of General Psychology, Vol. 5 No. 4, pp. 323-370.

Bolls, P., Lang, A. and Potter, R. (2001), "The Effects of Message Valence and Listener Arousal on Attention, Memory, and Facial Muscular Responses to Radio Advertisements", Communication Research, Vol. 28 No. 5, pp. 627-651.

Bradley, M., Codispoti, M., Cuthbert, B. and Lang, P. J. (2001), "Emotion and motivation I: Defensive and appetitive reactions in picture processing”, Emotion, Vol. 1 No. 3, pp. 276-298.

Brakus, J., Schmitt, B. and Zarantonello, L. (2009), "Brand Experience: What Is It? How Is It Measured? Does It Affect Loyalty?”, Journal of Marketing, Vol. 73 No. 3, pp. 52-68.

Cacioppo, J. and Gardner, W. (1999), "Emotion”, Annual Review of Psychology, Vol. 50 No. 1, pp. 191-214.

Carroll, B. and Ahuvia, A. (2006), "Some antecedents and outcomes of brand love”, Marketing Letters, Vol. 17 No. 2, pp. 79-89.

Chan-Olmsted, S. (2011), "Media Branding in a Changing World: Challenges and Opportunities 2.0", International Journal on Media Management, Vol. 13 No. 1, pp. $3-19$.

Chan-Olmsted, S. (2006), Competitive Strategy for Media Firms: Strategic and Brand Management in Changing Media Markets. Routledge, London.

Chan-Olmsted, S. and Cha, J. (2008), "Exploring the antecedents and effects of brand images for television news: An application of brand personality construct in a multichannel news environment", The International Journal on Media Management, Vol. 10 No. 1, pp. $32-45$. 
Chan-Olmsted, S. and Shay, R. (2015), "Media Branding 3.0: From Media Brands to Branded Entertainment and Information”, in Siegert, G., Förster, K., Chan-Olmsted, S. and Ots, M. (Eds.), Handbook of Media Branding. Springer, Cham, pp. 11-32.

Chartrand, L. (2005), "The role of conscious awareness in consumer behavior", Journal of Consumer Psychology, Vol. 15 No. 3, pp. 203-210.

Coan, J. and Allen, J. (2004), "Frontal EEG asymmetry as a moderator and mediator of emotion”, Biological Psychology, Vol. 67 No. 1-2, pp. 7-50.

Carroll, B. and Ahuvia, A. (2006), "Some antecedents and outcomes of brand love", Marketing Letters, Vol. 17 No. 2, pp. 79-89.

Cohen, B., Davidson, R., Senulis, J., Saron, C. and Weisman, D. (1992), "Muscle tension patterns during auditory attention”, Biological psychology, Vol. 33 No. 2, pp. 133-156.

Davidson, R. (2003), “Affective neuroscience and psychophysiology: Toward a synthesis", Psychophysiology, Vol. 40 No. 5, pp. 655-665.

Esch, F., Möll, T., Schmitt, B., Elger, C., Neuhaus, C. and Weber, B. (2012), "Brands on the brain: Do consumers use declarative information or experienced emotions to evaluate brands?", Journal of Consumer Psychology, Vol. 22 No. 1, pp. 75-85.

Esch, F., Langner, T., Schmitt, B. and Geus, P. (2006), “Are brands forever? How brand knowledge and relationships affect current and future purchases", Journal of Product \& Brand Management, Vol. 15 No. 2, pp. 98-105.

Flanagin, A. and Metzger, M. (2007), "The role of site features, user attributes, and information verification behaviors on the perceived credibility of web-based information", New Media \& Society, Vol. 9 No. 2, pp. 319-342.

Fournier, S. (1998), “Consumers and Their Brands: Developing Relationship Theory in Consumer Research”, Journal of Consumer Research, Vol. 24 No. 4, pp. 343-353. 
Fox, J., Lang, A., Chung, Y., Lee, S., Schwartz, N. and Potter, D. (2004), "Picture This: Effects of Graphics on the Processing of Television News", Journal of Broadcasting \& Electronic Media, Vol. 48 No. 4, pp. 646-674.

Fridlund, A. and Cacioppo, J. (1986), “Guidelines for human electromyographic research", Psychophysiology, Vol. 23 No. 5, pp. 567-589.

Goldsmith, R., Lafferty, B. and Newell, S. (2000), “The Impact of Corporate Credibility and Celebrity Credibility on Consumer Reaction to Advertisements and Brands", Journal of Advertising, Vol. 29 No. 3, pp. 43-54.

Grabe, M., Lang, A. and Zhao, X. (2003), "News Content and Form Implications for Memory and Audience Evaluations", Communication Research, Vol. 30 No. 4, pp. 387-413.

Harmon-Jones, E. (2003), "Clarifying the emotive functions of asymmetrical frontal cortical activity", Psychophysiology, Vol. 40 No. 6, pp. 838-848.

Herbig, P. and Milewicz, J. (1995), "To be or not to be...credible that is: a model of reputation and credibility among competing firms", Marketing Intelligence \& Planning, Vol. 13 No. 6, pp. 24-33.

Hoeffler, S. and Keller, K. (2003), "The marketing advantages of strong brands", Brand Management, Vol. 10, pp. 421-445.

Hovland, C., Janis, I. and Kelley, H. (1953), Communication and persuasion; psychological studies of opinion change, Yale University Press, New Haven, CT.

Johnson, D. and Grayson, K. (2005), "Cognitive and affective trust in service relationships", Journal of Business Research, Vol. 58 No. 4, pp. 500-507.

Kang, H. and Sundar, S. (2016), "When self is the source: effects of media customization on message processing", Media Psychology, Vol. 19 No. 4, pp. 561-588.

Keller, K. (2003), "Brand Synthesis: The Multidimensionality of Brand Knowledge”, Journal of Consumer Research, Vol. 29 No. 4, pp. 595-600. 
Klimesch, W. (1999), "EEG alpha and theta oscillations reflect cognitive and memory performance: a review and analysis”, Brain Research Reviews, Vol. 29 No. 2-3, pp. $169-195$.

Kohring, M. and Matthes, J. (2007), “Trust in News Media Development and Validation of a Multidimensional Scale”, Communication Research, Vol. 34 No. 2, pp. 231-252.

Krebs, I. (2017), "Does the brand affect the quality perception of news articles?-An experimental study on news media brands in Switzerland." Journal of Media Business Studies, Vol. 4, pp. 235-256.

Krebs, I. and Siegert, G. (2015), "20 Years of Research on Media Brands and Media Branding“, in Siegert, G., Förster, K., Chan-Olmsted, S. and Ots, M. (Eds.), Handbook of Media Branding. Springer, Cham, pp. 33-49.

Kätsyri, J., Ravaja, N. and Salminen, M. (2012), “Aesthetic images modulate emotional responses to reading news messages on a small screen: A psychophysiological investigation” International Journal of Human Computer Studies, Vol. 70 No. 1, pp. $72-87$.

Lang, A. (2000), “The limited capacity model of mediated message processing”, Journal of Communication, Vol. 50 No. 1, pp. 46-70.

Lang, A., Borse, J., Wise, K. and David, P. (2002), "Captured by the World Wide Web Orienting to Structural and Content Features of Computer-Presented Information”, Communication Research, Vol. 29 No. 3, pp. 215-245.

Lang, A., Kurita, S., Gao, Y. and Rubenking, B. (2013a), "Measuring Television Message Complexity as Available Processing Resources: Dimensions of Information and Cognitive Load" Media Psychology, Vol. 6 No. 2, pp. 129-153. 
Lang, A., Sanders-Jackson, A., Wang, Z. and Rubenking, B. (2013b), “Motivated message processing: How motivational activation influences resource allocation, encoding, and storage of TV messages", Motivation and Emotion, Vol. 37 No. 3, pp. 508-517.

Lang, P. J. (1995), “The emotion probe: Studies of motivation and attention", American Psychologist, Vol. 50 No. 5, pp. 372-385.

Lang, P. J., Greenwald, M., Bradley, M. and Hamm, A. (1993), “Looking at pictures: affective, facial, visceral, and behavioral reactions", Psychophysiology, Vol. 30 No. 3, pp. 261273.

Lindsley, D. and Wicke, J. (1974), “The electroencephalogram: Autonomous electrical activity in man and animals", in Thompson, R. and Patterson, M. (Eds.), Bioelectric Recording Techniques: Electroencephalography and Human Brain Potentials, Methods in Physiological Psychology, Academic Press, New York and London, pp. 3-83.

Loewenstein, G. and Lerner, J. (2003), “The role of affect in decision making”, in Davidson, R., Scherer, K. and Hill, G. (Eds.), Handbook of affective sciences, Oxford University Press, Oxford, pp. 619-642.

Malmelin, N. and Moisander, J. (2014), "Brands and Branding in Media ManagementToward a Research Agenda”, International Journal on Media Management, Vol. 16 No. 1, pp. 9-25.

Mauri, M., Cipresso, P., Balgera, A., Villamira, M. and Riva, G. (2011), "Why is Facebook so successful? Psychophysiological measures describe a core flow state while using Facebook", Cyberpsychology, Behavior, and Social Networking, Vol. 14 No. 12, pp. $723-731$.

McDowell, W. (2006), "Issues in marketing and branding”, in Albarran, A., Chan-Olmsted, S. and Wirth. M. (Eds.), Handbook of media management and economics, Lawrence Erlbaum, Mahwah, NJ, pp. 229-250. 
Miller, J. and Krosnick, J. (2000), "News media impact on the ingredients of presidential evaluations: Politically knowledgeable citizens are guided by a trusted source", American Journal of Political Science, Vol. 44 No. 2, pp. 301-315.

Moorman, M., Neijens, P. and Smit, E. (2002), "The effects of magazine-induced psychological responses and thematic congruence on memory and attitude toward the ad in a real-life setting", Journal of Advertising, Vol. 31 No. 4, pp. 27-40.

Newhagen, J. and Reeves, B. (1992), “The Evening's Bad News: Effects of Compelling Negative Television News Images on Memory", Journal of Communication, Vol. 42 No. 2, pp. 25-41.

Paulhus, D. (2002), “Socially desirable responding: The evolution of a construct”, in H. Braun and Jackson, D. (Eds.), The role of constructs in psychological and educational measurement, Lawrence Erlbaum, Mahwah, NJ, pp. 37-48.

Potter, R. and Bolls, P. (2012), Psychophysiological measurement and meaning: Cognitive and emotional processing of media. Routledge.

Ravaja, N. (2004), “Contributions of psychophysiology to media research: Review and recommendations", Media Psychology, Vol. 6 No. 2, pp. 193-235.

Ravaja, N., Aula, P., Falco, A., Laaksonen, S., Salminen, M. and Ainamo, A. (2015), “Online News and Corporate Reputation”, Journal of Media Psychology, Vol. 27 No. 3, pp. $118-133$

Ravaja, N., Saari, T., Kallinen, K. and Laarni, J. (2006), "The Role of Mood in the Processing of Media Messages From a Small Screen: Effects on Subjective and Physiological Responses” Media Psychology, Vol. 8 No. 3, pp. 239-265.

Rodero, E., Potter, R. and Prieto, P. (2017), "Pitch range variations improve cognitive processing of audio messages", Human communication research, Vol. 43 No 3, pp. 397-413. 
Rozin, P. and Royzman, E. (2001), "Negativity Bias, Negativity Dominance, and Contagion", Personality and Social Psychology Review, Vol. 5 No. 4, pp. 296-320.

Russell, J. (1980), “A Circumplex Model of Affect”, Journal of Personality and Social Psychology, Vol. 39, pp. 1161-1178.

Schaefer, M. and Rotte, M. (2007), “Thinking on luxury or pragmatic brand products: Brain responses to different categories of culturally based brands", Brain Research, 1165, pp. 98-104.

Schneider, S. and Laurion, S. (1993), “Do we know what we've learned from listening to the news?", Memory \& Cognition, Vol. 21 No. 2, pp. 198-209.

Schumann, D. and Thorson, E. (1990), “The influence of viewing context on commercial effectiveness: A selection-processing model", Current issues and research in advertising, Vol. 12 No. 1-2, pp. 1-24.

Siegert, G., Gerth, M. and Rademacher, P. (2011), "Brand Identity-Driven Decision Making by Journalists and Media Managers_-The MBAC Model as a Theoretical Framework", International Journal on Media Management, Vol. 13 No 1, pp. 53-70.

Simons, R., Detenber, B., Cuthbert, B., Schwartz, D., and Reiss, J. (2003), “Attention to Television: Alpha Power and Its Relationship to Image Motion and Emotional Content”, Media Psychology, Vol. 5 No. 3, pp. 283-301.

Soscia, I. (2007), “Gratitude, delight, or guilt: The role of consumers' emotions in predicting post-consumption behaviors", Psychology and Marketing, Vol. 24 No. 10, pp. 871894.

Sundar, S. and Kalyanaraman, S. (2004), "Arousal, Memory, and Impression-Formation Effects of Animation Speed in Web Advertising”, Journal of Advertising, Vol. 33 No. 1, pp. 7-17. 
Sommer, C. (2015), "Media brands and the advertising market: Exploring the potential of branding in media organizations' b2b relationships”, in Siegert, G., Förster, K., ChanOlmsted, S. and Ots, M. (Eds.), Handbook of media branding, Springer, Berlin, pp. $102-115$.

Sundar, S. (2008), “The MAIN Model: A Heuristic Approach to Understanding Technology Effects on Credibility", in Metzger, J. and Flanagin, A. (Eds.), Digital media, youth, and credibility. MIT Press, Cambridge, MA, pp. 73-100.

Tassinary, L. and Cacioppo, J. (2000), “The skeletomuscular system: Surface electromyography", in Cacioppo, J., Tassinary, L. and G. Berntson (Eds.), Handbook of psychophysiology, Cambridge University Press, New York, pp. 163-199.

Thomson, M., MacInnis, D. and Park, C. (2005), “The ties that bind: Measuring the strength of consumers' emotional attachments to brands", Journal of Consumer Psychology, Vol. 15 No. 1, pp. 77-91.

Tungate, M. (2004). Media monoliths: How great media brands thrive and survive. Kogan Page Publishers, London.

Veloutsou, C. and Moutinho, L. (2009), "Brand relationships through brand reputation and brand tribalism", Journal of Business Research, Vol. 62 No. 3, pp. 314-322.

Villi, M., Matikainen, J. and Khaldarova, I. (2016), "Recommend, Tweet, Share: UserDistributed Content (UDC) and the Convergence of News Media and Social Networks", in Lugmayr, A. and Dal, Z. (Eds.), Media Convergence Handbook, Springer, Berlin, pp. 289-306.

Walla, P., Brenner, G. and Koller, M. (2011), “Objective Measures of Emotion Related to Brand Attitude: A New Way to Quantify Emotion-Related Aspects Relevant to Marketing”, PLoS ONE, Vol. 6 No. 11, e26782. 
Wallace, E., Buil, I. and de Chernatony, L. (2014), "Consumer engagement with selfexpressive brands: brand love and WOM outcomes", Journal of Product \& Brand Management, Vol. 23 No. 1, pp. 33-42.

Wise, K., Alhabash, S. and Eckler, P. (2013), “"Window' shopping online: cognitive processing of general and specific product windows", Journal of interactive advertising, Vol. 13 No. 2, pp. 88-96.

Zechmeister, E. and Nyberg, S. (1982), Human memory: An introduction to research and theory. Brooks/Cole, Monterey, CA. 
Running head: BRAND AS A COGNITIVE MEDIATOR

Table 1

Contrasts of media brands

Contrasts

Media Brands

1

3

4
All media brands

Traditional media brands

Familiar traditional media

High-credibility traditional media

Familiar social media brand
Control media brand

Social media brands

Unfamiliar traditional media

Low-credibility traditional media

Traditional media brands 
BRAND AS A COGNITIVE MEDIATOR

Table2

Means for Self-Reports, Facial EMG, EEG and Memory Tests by A Priori News Valence and Involvement

News Valence

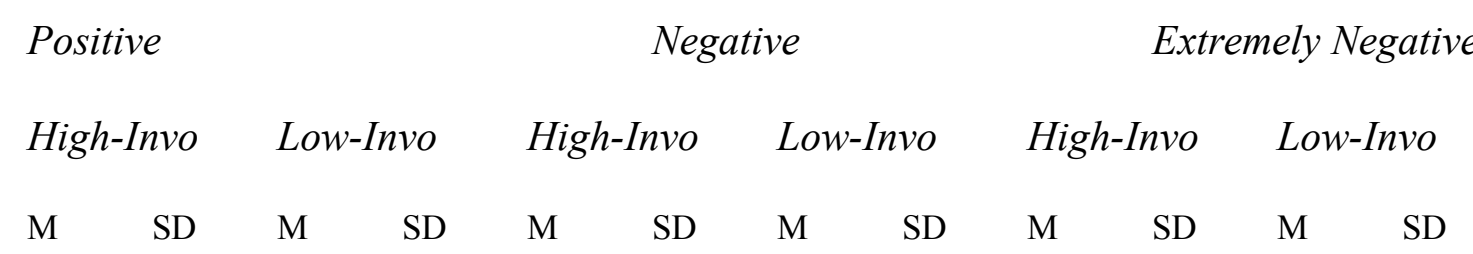

Self Reports

Emotional valence

$\begin{array}{lllllllllllll}6.46 & 1.25 & 5.93 & 1.20 & 3.27 & 1.28 & 3.80 & 1.15 & 2.87 & 1.14 & 2.93 & 1.13 & 53.00 * * * \\ 4.32 & 1.74 & 3.48 & 1.62 & 4.54 & 1.83 & 3.38 & 1.53 & 4.26 & 1.63 & 4.02 & 1.67 & 10.70 * * *\end{array}$

Emotional Arousal

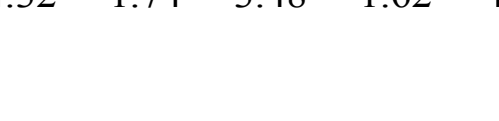


BRAND AS A COGNITIVE MEDIATOR

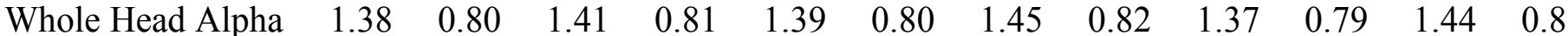

Memory Tests

Recognition

$\begin{array}{lllll}1.81 & 0.83 & 1.84 & 0.88 & 2 .\end{array}$

Free recall

$\begin{array}{lllll}0.37 & 0.48 & 0.32 & 0.46 & 0.33\end{array}$

0.75

1.82

$0.83 \quad 1.90$

$\begin{array}{lll}0.88 & 1.87 & 0.82\end{array}$

$10.01 * * *$

Note. Self-report measures were recorded on a $1-9$ scale. Facial EMG $=$ electromyography, EEG $=$ electroencephalography. ${ }^{*} p<.05 .{ }^{* *} p<.01 .{ }^{* * *} p<.001$. 
BRAND AS A COGNITIVE MEDIATOR

Table 3

Means for Self-Reports, Facial EMG, EEG and Memory Tests by Media Brands

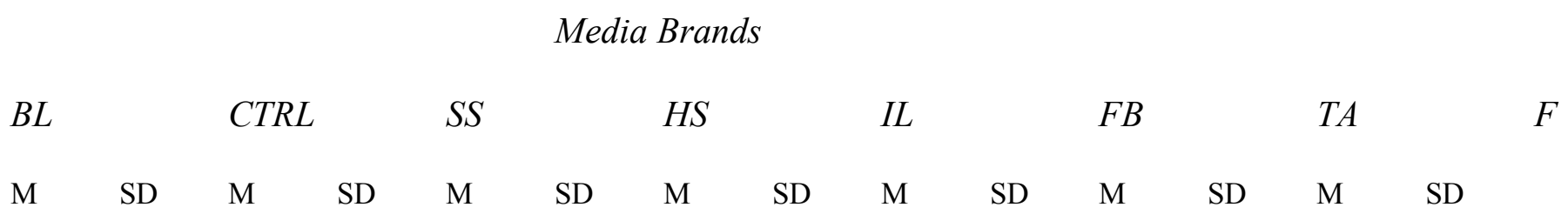

Self Reports

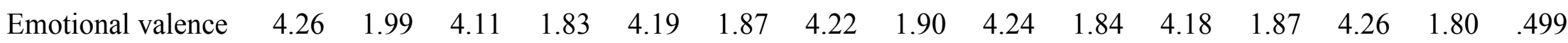

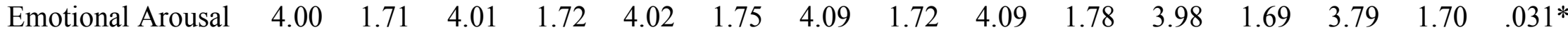

\section{Facial EMG}

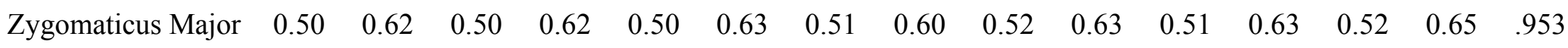

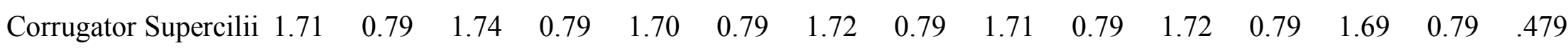

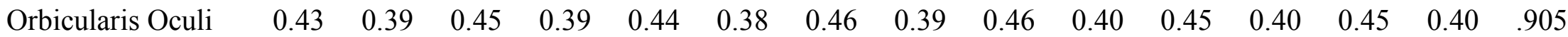

EEG

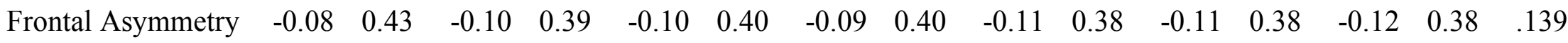

$\begin{array}{llllllllllllllll}\text { Frontal Alpha } & 1.36 & 0.81 & 1.39 & 0.83 & 1.36 & 0.80 & 1.37 & 0.80 & 1.34 & 0.82 & 1.37 & 0.82 & 1.37 & 0.80 & .050^{*}\end{array}$

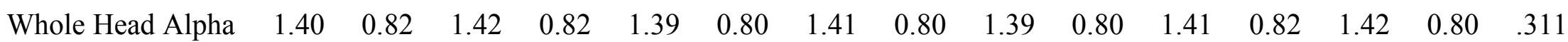


BRAND AS A COGNITIVE MEDIATOR

Memory Tests

$\begin{array}{lccccccccccccccc}\text { Recognition } & 1.95 & 0.83 & 1.97 & 0.88 & 1.92 & 0.82 & 1.92 & 0.83 & 1.85 & 0.79 & 1.78 & 0.86 & 1.85 & 0.85 & .025^{*} \\ \text { Free recall } & 0.63 & 0.027 & 0.69 & 0.028 & 0.68 & 0.024 & 0.67 & 0.023 & 0.62 & 0.025 & 0.74 & 0.021 & 0.65 & 0.027 & .023\end{array}$

Note. Self-report measures were recorded on a 1-9 scale. Facial EMG $=$ electromyography, EEG $=$ electroencephalography. ${ }^{*} p<.05 .{ }^{* *} p<.01 .{ }^{* * *} p<.001$. 